\title{
Vessel-wall Imaging for Primary Angiitis of Central Nervous System Diagnosis
}

\author{
Primer Merkezi Sinir Sistemi Vasküliti Tanısında Damar Duvarı Görüntülemesinin Yeri
}

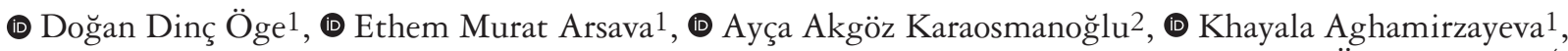

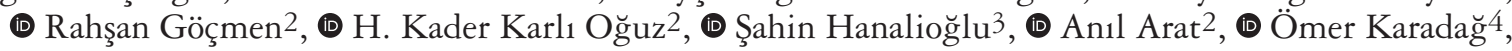

(1) Mehmet Akif Topçuoğlu ${ }^{1}$

${ }^{1}$ Hacettepe University Faculty of Medicine, Department of Neurology, Ankara, Turkey

2Hacettepe University Faculty of Medicine, Department of Radiology, Ankara, Turkey

3Hacettepe University Faculty of Medicine, Department of Neurosurgery, Ankara, Turkey

${ }^{4}$ Hacettepe University Faculty of Medicine, Department of Internal Medicine, Ankara, Turkey

Keywords: Vasculitis, central nervous system, arteriopathy, atherosclerosis, vasoconstriction

Anahtar Kelimeler: Vaskülit, santral sinir sistemi, arteriopati, ateroskleroz, vazokonstriksiyon

\section{Dear Editor,}

A 40-year-old woman with a history of stroke and hyperlipidemia on regular aspirin and clopidogrel presented to the emergency department with a 2-hour right hemiparesis and aphasia episode. Admission diffusion-weighted and fluid-attenuated inversion recovery magnetic resonance imaging (MRI) disclosed acute and chronic accumulating small ischemic lesions along with multiple hyperintense vessels signs indicative of hemispheric hypoperfusion (Figure 1A, C, D, 2A). MR angiography revealed occlusion of the left middle cerebral artery (MCA) and internal carotid artery (ICA), with filling of the third-order branches of the left MCA inferior division via distal branches of a left posterior cerebral artery, and the left anterior cerebral artery (ACA) was cross-filling from the right. Findings were confirmed on catheter angiography performed after discharge with a provisional diagnosis of hemodynamic transient ischemic attack (Figure 2B, C). On catheter angiography, there were no moyamoya anastomoses around the occluded left MCA proximal portion. As a remarkable finding, significant stenosis and wall irregularity were noted in the right terminal ICA, proximal portions of MCA, and ACA (Figure 2D). Detailed peripheral blood markers for systemic vasculitic, inflammatory, autoimmune, infectious and prothrombotic conditions were normal or negative. A cerebrospinal fluid (CSF) examination, including Varicella-zoster polymerase chain reaction, was normal. A whole-body vascular positron emission tomography scan showed no signs of systemic vasculitis.

During hospitalization, the patient had two more similar episodes, one after discontinuation of clopidogrel for lumbar puncture, and the other during strenuous exercise. Repeated diffusion-weighted imaging showed new small cortical infarcts (Figure 1B). Perfusion studies displayed left-sided severe hypoperfusion, but also significant right-sided hemodynamic compromise, and single-photon emission computed tomography with intravenous acetazolamide documented diminished vasomotor reactivity bilaterally.

At this stage, vessel wall MRI was performed, eventually leading to a diagnosis. This imaging showed intense, homogenous, and mostly concentric gadolinium enhancement and thickening of the right terminal ICA, MCA, and ACA vessel wall (Figure 3A, B, C, Figure 4) suggestive of vasculitis. Based on this highly specific appearance, plus affirmative clinical and laboratory findings, pulse steroid and cyclophosphamide was initiated for the induction phase of treatment of primary angiitis of the CNS. The patient was discharged with oral glucocorticoid and pulse cyclophosphamide, along with dual antiplatelet therapy.

Address for Correspondence/Yazışma Adresi: Doğan Dinç Öge MD, Hacettepe University Faculty of Medicine, Department of Neurology, Ankara, Turkey Phone: +90312305 25 85 E-mail: dogandincoge@gmail.com ORCID: orcid.org/0000-0001-8103-4779

Received/Geliş Tarihi: 17.10.2020 Accepted/Kabul Tarihi: 21.12.2020

${ }^{\circ}$ Copyright 2021 by Turkish Neurological Society

Turkish Journal of Neurology published by Galenos Publishing House. 


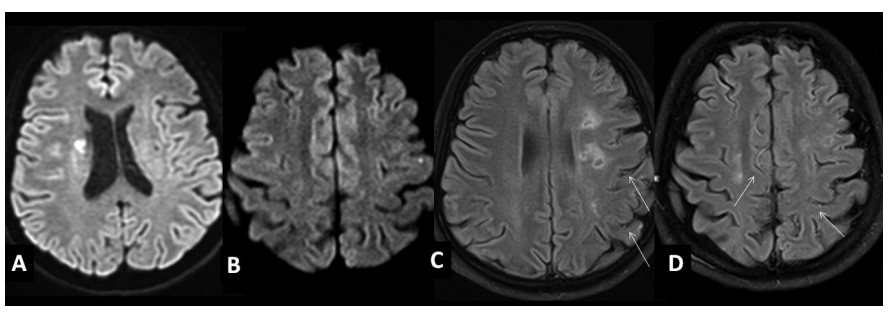

Figure 1. A) DWI showed a right-sided subacute deep small infarction on initial evaluation; B) DWI: Punctate cortical acute infarction in the left precentral gyrus detected at the time of the second TIA episode happened during hospitalization; C, D) FLAIR: Chronic watershed infarctions involving both centrum semiovale more on the left along with sulcal serpentiginous hyperintense vessels indicating low perfusion status (arrows)

DWI: Diffusion-weighted imaging, FLAIR: Fluid-attenuated inversion recovery imaging, TIA: Transient ischemic attack

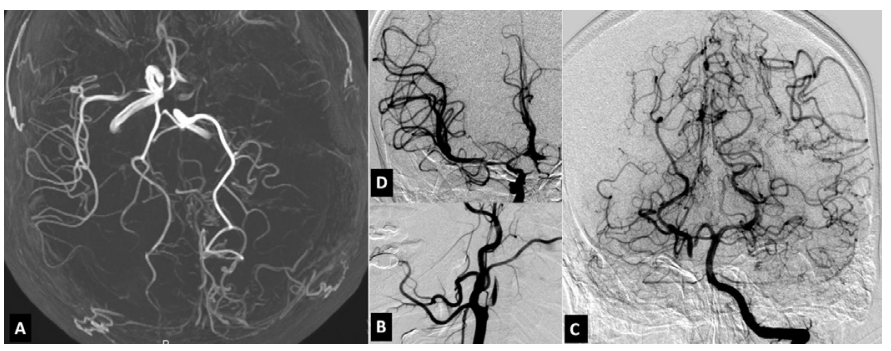

Figure 2. A) 3D-TOF MR angiography showed no signal of the middle cerebral artery (MCA) and intracranial internal carotid artery (ICA) on the left, and significant narrowing of proximal MCA, inlet of the anterior cerebral artery (ACA) and terminal ICA on the right. B) Occlusion of left cervical ICA after smooth tapering. C) Left PCA distal branches reconstituting the distal left MCA territory as well as distal pericallosal left ACA branches. D: Regional vessel wall irregularity and luminal narrowing of proximal MCA, ACA and terminal ICA on the right as seen on digital subtraction angiography images

3D-TOF MR: 3-dimensional time of flight magnetic resonance, PCA: Posterior cerebral artery

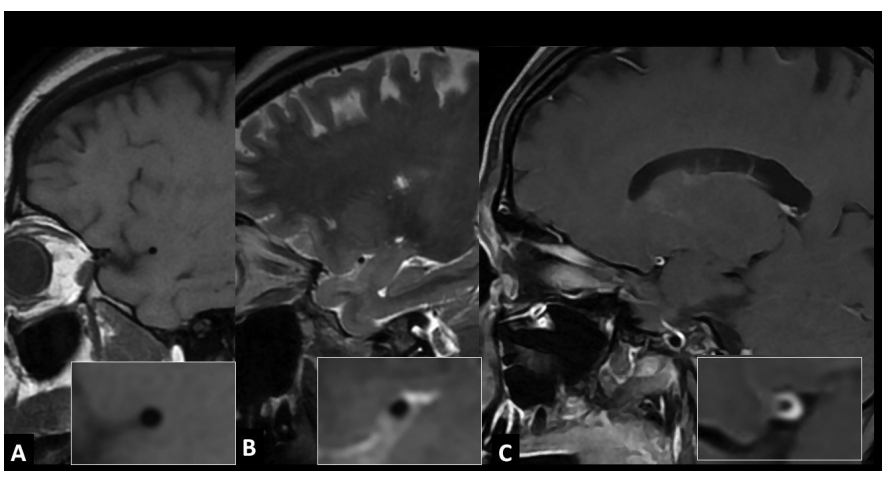

Figure 3. Sagittal T1 weighted, T2-weighted and contrast-enhanced vessel wall MR imaging performed on a $3 \mathrm{~T}$ MR scanner utilizing a 3-dimensional turbo spin-echo sequence: Intense homogenous gadolinium enhancement and thickening visible along the wall of the very proximal left MCA segment (boxes indicate x10 magnification)

MR: Magnetic resonance, MCA: Middle cerebral artery

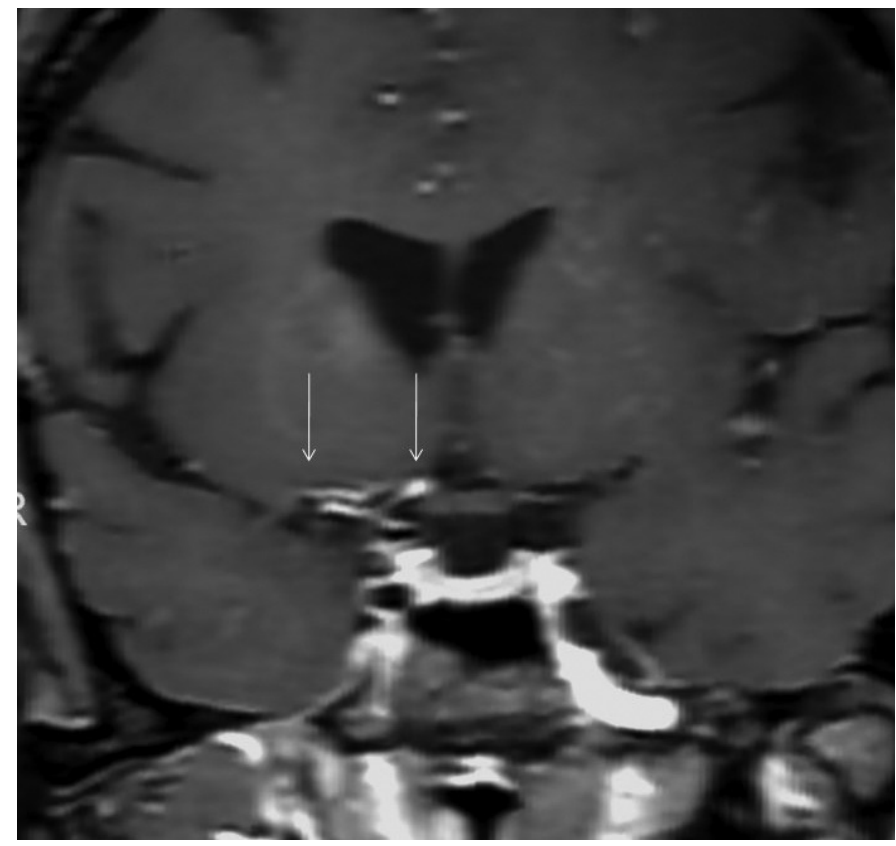

Figure 4. Coronal reconstructions of enhanced vessel wall images documented clear homogenous wall enhancement of the terminal intracranial internal carotid, proximal middle cerebral and anterior cerebral arteries on the right (arrows)

Vessel wall imaging, also known as black blood MRI, is a relatively new, developing, and not widely recognized MR modality. It is based on the suppression of luminal blood and CSF signal with MR technology using high-resolution, multiplanar acquisitions, and multiple tissue weightings $(1,2)$. To attain high spatial resolution, a $\geq 3$-Tesla magnet strength is required. It is suggested to be efficient in differentiating angiitis, atherosclerosis, vasoconstriction, moyamoya disease, and dissection involving intracranial first-order vessels. Although regional, sometimes multifocal, intense and concentric wall thickening and enhancement are present in angiitis, focal, eccentric, and a lesser degree of contrast enhancement is suggestive of atherosclerotic disease (3). Multisegmental concentric narrowing without contrast penetrance would favor vasoconstriction, and focal eccentric thickening with intramural hematoma is usually seen in arterial dissection. That is, this MR modality makes it possible to diagnose inflammatory cerebral large vessel arteriopathies where biopsy is not an option (4). A vignette of how it changes the diagnosis strategy is presented herein.

\section{Ethics}

Informed Consent: Written informed consent was obtained. Peer-review: Externally and internally peer-reviewed.

\section{Authorship Contributions}

Surgical and Medical Practices: D.D.Ö., E.M.A., A.A.K., K.A., R.G., H.K.K.O., Ş.H., A.A., Ö.K., M.A.T., Concept: D.D.Ö., E.M.A., A.A.K., M.A.T., Design: D.D.Ö., E.M.A., M.A.T., Data Collection or Processing: D.D.Ö., E.M.A., A.A.K., 
K.A., R.G., H.K.K.O., Ş.H., A.A., Ö.K., M.A.T., Analysis or Interpretation: D.D.Ö., E.M.A., A.A.K., K.A., R.G., H.K.K.O., S..H., A.A., Ö.K., M.A.T., Literature Search: D.D.Ö., A.A.K., M.A.T., Writing: D.D.Ö., M.A.T.

Conflict of Interest: No conflict of interest was declared by the authors.

Financial Disclosure: The authors declared that this study received no financial support.

\section{References}

1. Kuker W, Gaertner S, Nagele T, et al. Vessel wall contrast enhancement: a diagnostic sign of cerebral vasculitis. Cerebrovasc Dis 2008;26:23-29.
2. Mandell DM, Mossa-Basha M, Qiao Y, et al. Intracranial vessel wall MRI: Principles and expert consensus recommendations of the American Society of Neuroradiology. AJNR Am J Neuroradiol 2017;38:218-229.

3. Leao DJ, Agarwal A, Mohan S, Bathla G. Intracranial vessel wall imaging: applications, interpretation, and pitfalls. Clin Radiol 2020;75:730-739.

4. Singhal AB, Topcuoglu MA, Fok JW, et al. Reversible cerebral vasoconstriction syndromes and primary angiitis of the central nervous system: clinical, imaging, and angiographic comparison. Ann Neurol 2016;79:882-894. 